\title{
NOVO SC.GOV.BR: ANÁLISE DO PERFIL DE VISITANTES, CONTEÚDOS E SATISFAÇÃO DOS USUÁRIOS
}

\section{NEW SC.GOV.BR: USER PROFILE ANALYSIS, CONTENT IDENTIFICATION AND USER SATISFACTION}

\author{
Daniel Werle1, Esp.; \\ Lauren de Lima², Esp.; \\ Renata Assunçãoª , Msc.
}

(1) Universidade do Estado de Santa Catarina - Udesc

e-mail: danielrw@gmail.com

(2) Universidade do Estado de Santa Catarina - Udesc e-mail: laurenlima10@gmail.com

(3) Universidade do Vale de Santa Catrina - Univali e-mail: reassuncao@gmail.com

Arquitetura da Informação, Design de Interação, Governo Eletrônico

Este artigo apresenta o resultado de uma pesquisa feita com usuários do site do Governo do Estado de Santa Catarina (www.sc.gov.br). A pesquisa teve como objetivo identificar o perfil dos visitantes do site de acordo com categorias pré-estabelecidas, identificar os assuntos mais buscados, segmentando pelos perfis identificados e medir o grau de satisfação utilizando a ferramenta Net Promoter Score. Para a coleta de dados, utilizou-se um questionário on-line estruturado disponibilizado entre 19 e 29 de janeiro de 2016. Obteve-se 1.407 respostas, com resultados estatisticamente relevantes em relação à amostra. Foi possível identificar os diversos públicos que acessam o site, entender quais os conteúdos mais buscados por cada um destes e seu grau de satisfação. Concluiu-se que outros métodos ergonômicos de avaliação, como criação de personas, podem ser usadas para complementar a atual pesquisa bem como chegar a informações mais consolidadas.

\section{Information Architecture, Interaction Design, E-government}

This article presents the result of a research conducted with visitors from Santa Catarina's State Website (www.sc.gov.br). The aim of this research was to: map the user profile of the website visitors according to pre- 
$16^{\circ}$ Ergodesign - Congresso Internacional de Ergonomia e Usabilidade de Interfaces Humano Tecnológica: Produto, Informações Ambientes Construídos e Transporte

$16^{\circ}$ USIHC - Congresso Internacional de Ergonomia e Usabilidade de Interfaces Humano Computador

established categories; identify the most seeked topics according to each user profile; and measure the user satisfaction with the Net Promoter Score tool. The data was gathered by the application of questionnaire form available from January 19th till 29th of 2016. Statistically relevant results were achieved with 1.407 complete answers gathered. It was possible to identify diverse profiles from users accessing the website, understand which were the most searched for content and degree of satisfaction for each profile. Other ergonomic methods of evaluation, as "persona" creation, can be used to add depth to the current research, as well develop more consolidated information.

\section{Introdução}

A complexidade dos problemas e a velocidade das mudanças que ocorrem na sociedade hoje, em função das tecnologias de informação e comunicação (TICs), tem levado as organizações públicas e privadas a uma corrida para revisar a forma como se comunicam com seus públicos de interesse. Se nas empresas é necessário inovar para sobreviver, no setor público é necessário inovar para ter representatividade (AGUNE, et al, 2014). Para garantir essa representatividade é possível usar as novas abordagens de design para as plataformas web. Segundo Rover e Galindo (2010)

\footnotetext{
...na concepção de interfaces digitais para eGov considerando as características e necessidades específicas de seus usuários, fazendo com que os cidadãos enquanto usuários não se distanciem da intenção da esfera pública de promover uma maior interação entre o conteúdo informacional e serviços disponibilizados pelos e-Gov. Seguir uma abordagem de Design Centrado no Usuário para desenvolver interfaces digitais para e-Gov pode ser uma forma de evitar que isso aconteça.
}

Já é ponto passivo que atuar nessa frente é o próximo passo na inovação da comunicação em gestão pública e que as avaliações ergonômicas são ferramentas indicadas para transformar repositórios de conteúdo em plataformas amigáveis e difusores mais eficientes de informação ao grande público. (PREECE, 2002).

O questionário detalhado e interpretado neste artigo foi uma das metodologias aplicadas durante o projeto de redesign do atual site do Governo do Estado de Santa Catarina - www.sc.gov.br Na criação do site atual, lançado em 2013, não houve a utilização de uma aplicação de métodos ergonômicos para identificar o perfil de público e, principalmente, adequar a arquitetura da informação aos usuários do site, o que se buscou corrigir no novo projeto, iniciado em 2016 e a ser lançado em 2017.

Para este novo projeto, buscou-se adaptar a abordagem de Goal-directed Design proposta por Cooper (2007), que afirma que o papel do design neste processo é o de "prover a verdadeira definição do produto, baseado nas necessidades do usuário, necessidades do negócio e limitações da tecnologia" (COOPER, 2007) (Figura 1). O autor ainda reforça que, nesta abordagem, o designer também possui o papel de pesquisador, pois nesta abordagem é ele quem traduz o conhecimento adquirido em pesquisa em especificação de projeto.

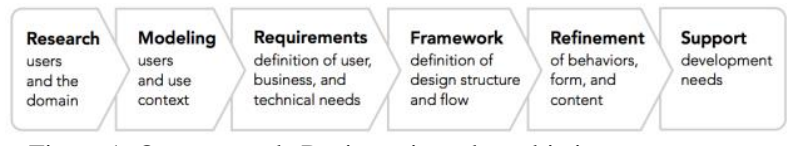

Figura 1: O processo de Design orientado a objetivos proposto por Cooper (2007)

Dentro da etapa de pesquisa, o autor explica que pesquisas de mercado qualitativas e dados quantitativos de métricas (analytics) trazem insumos para as etapas qualitativas de pesquisa com usuários (Figura 2). 


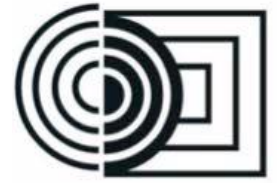
CINAHPA

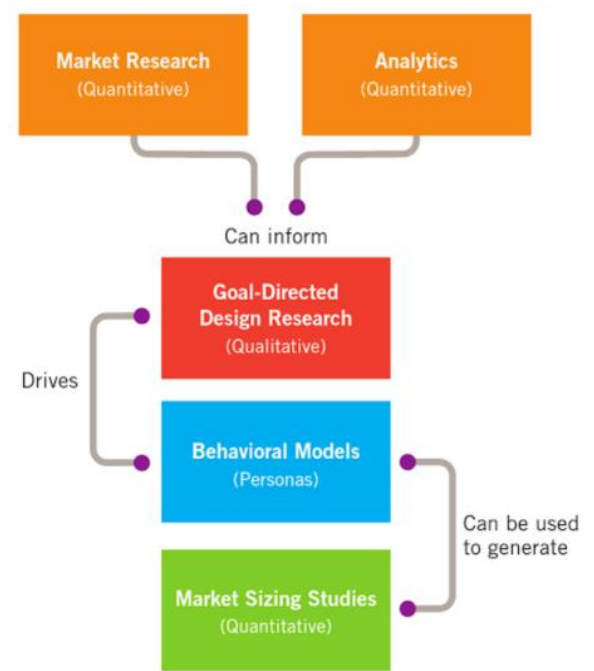

Figura 2: a relação entre pesquisa quantitativa e qualitativa na Pesquisa em Design Centrado em Objetivos (COOPER, 2014)

Com o intuito de gerar dados quantitativos para uma posterior pesquisa qualitativa, um questionário foi aplicado aos visitantes do site www.sc.gov.br, com o intuito de:

- identificar os diversos públicos que visitam o site;

- identificar os conteúdos de maior interesse;

- medir a satisfação dos visitantes

O questionário foi elaborado a partir de um planejamento pré-definido, de forma estruturada, em condições controladas, respondendo a propósitos pré-definidos. A pesquisa utilizou como instrumento para captura das respostas a ferramenta Hotjar, o que a transforma em uma observação sistemática indireta, apoiando-se no uso desse objeto para registrar as informações (BARBETTA, 2015).

De acordo com Lemos et al (2004) “....as interfaces dos web sites de prefeituras e estados têm por tarefa facilitar o acesso a uma audiência por demais heterogênea, englobando cidadãos com características sociais, econômicas e culturais diversas". Não cabendo a esta avaliação ergonômica a criação de protótipos ou validação da arquitetura da informação vigente, mas sim, através de análise do $16^{\circ}$ Ergodesign - Congresso Internacional de Ergonomia e Usabilidade de Interfaces Humano Tecnológica: Produto, Informações Ambientes Construídos e Transporte

$16^{\circ}$ USIHC - Congresso Internacional de Ergonomia e Usabilidade de Interfaces Humano Computador

CINAHPA | 2017 - Congresso Internacional de Ambientes Hipermídia para Aprendizagem.

questionário extrair informações relevantes para gerar conceituações possíveis e orientações para produção de um novo site ou melhoria no site atual.

\section{Desenvolvimento}

\subsection{Método de pesquisa para identificação de público e necessidades}

A população de interesse do questionário foi restringida pela limitação geográfica de concentração dos indivíduos: moradores do Estado de Santa Catarina - considerado genérico e abrangente, pois o Governo atende a sociedade catarinense de uma maneira geral em suas diversas necessidades. Requisitando dos articulistas que o questionário fosse elaborado com extrema cautela.

Dentro desse recorte foi possível delimitar uma amostragem aleatória para todos os internautas considerados, sendo estes a população de interesse neste estudo (BARBETTA, 2015). Partindo dessa conceituação, foram selecionadas pessoas que acessaram o site no período e voluntariamente contribuíram com o questionário.

Essa generalização dos respondentes pode ser considerado o primeiro desafio para aplicação do questionário - não saber para quem perguntar - e, simultaneamente, se transforma numa oportunidade para identificar os clusters interessados e possíveis para adaptação das grandes áreas do site. Tendo em mãos os objetivos das análises claramente definidos:

a) Criar recomendações para melhorias na funcionalidade de um site governamental tornando-o mais adequado às necessidades dos usuários e focado numa arquitetura de informação melhorada.

Dessa forma foi possível delimitar duas grandes variáveis que podem ser estratificadas pelo questionário:

b) Identificar os perfis de público interessados na comunicação do governo 
e;

c) Definir entre esses públicos quais informações de principal interesse.

Com o intuito de definir o nível de confiança dos resultados diante do número de entrevistas, foi retro calculado tal valor pela fórmula do tamanho amostral (TRIOLA, 2008; SAURO \& LEWIS, 2012).

$$
n=\frac{p(1-p) Z^{2} N}{\varepsilon^{2}(N-1)+Z^{2} p(1-p)}
$$

onde:

n: Tamanho da amostra, neste caso igual ao número de pessoas que responderam a pesquisa 1407 para a primeira questão, 884 para a segunda e 736 para a terceira questão;

p: Proporção esperada de cada escolha de cada uma das opções de resposta possível, neste caso igual a 0,125 para a primeira questão, igual 0,167 para a segunda é igual a 0,091 para a terceira questão;

Z: Valor tabelado da distribuição normal para determinar o nível de confiança. O valor de $\mathrm{Z}$ é uma forma de expressar, de modo padronizado, a posição relativa de uma observação no interior de uma distribuição;

N: Tamanho da população, neste caso igual ao número de pessoas que visitaram o site - 36.984;

\section{E: Tamanho do intervalo de confiança (margem de erro) (0,01).2.2 Construção do questionário}

\author{
"Para garantir altas taxas de respostase \\ evitar resultados enganosos, mantenha seu \\ questionário curto e garanta que suas \\ perguntas estão bem escritas e fáceis de \\ serem respondidas." (NIELSEN, 2004)
}

Durante a construção do questionário, uma das $16^{\circ}$ Ergodesign - Congresso Internacional de Ergonomia e Usabilidade de Interfaces Humano Tecnológica: Produto, Informações Ambientes Construídos e Transporte

$16^{\circ}$ USIHC - Congresso Internacional de Ergonomia e Usabilidade de Interfaces Humano Computador

CINAHPA | 2017 - Congresso Internacional de Ambientes Hipermídia para Aprendizagem.

grandes preocupações dos pesquisadores era a de maximizar o número de respostas obtidas. Para tal foram utilizados questionários estruturados, onde as perguntas são devidamente formuladas e cuidase para não fugir a elas e as respostas são de múltipla escolha (BONI \& QUARESMA, 2005).

O questionário criado apresentou somente três perguntas:

1. A primeira buscava identificar o perfil dos visitantes do site. Inicialmente a classificação de públicos disponíveis no site www.pertodevoce.sc.gov.br foram usados como referências. Além de um levantamento com a equipe de assessoria de imprensa que apresentou o público "imprensa" como relevante.

2. A segunda tinha por objetivo conhecer os tipos de conteúdos mais buscados pelos usuários no site. As opções de resposta foram definidas com base nos tipos de conteúdos existentes nos sites a serem redesenhados.

3. A última pergunta avaliava o nível de satisfação dos visitantes do site. Conforme sugerido por Nielsen (2004), a ferramenta utilizada para medição de satisfação neste questionário foi a Net Promoter Score.

Uma sessão de pré-teste com quatro pessoas foi conduzida para validar a redação das perguntas e garantir que tanto as perguntas quanto as sugestões de respostas estavam claras e podiam ser facilmente compreendidas. Não foi necessário corrigir a redação de nenhum item. Ao final as perguntas feitas aos usuários foram: 


\section{$16^{\circ}$ \\ ERGODESIGN \\ USIHC CINAHPA}

$16^{\circ}$ Ergodesign - Congresso Internacional de Ergonomia e Usabilidade de Interfaces Humano Tecnológica: Produto, Informações Ambientes Construídos e Transporte

$16^{\circ}$ USIHC - Congresso Internacional de Ergonomia e Usabilidade de Interfaces Humano Computador

CINAHPA | 2017 - Congresso Internacional de Ambientes Hipermídia para Aprendizagem. a) "Com qual perfil abaixo você mais se identifica?"

b) "O que você está buscando no site?"

c) "Como foi sua experiência ao usaro site?"

Quadro 1: Redação final das perguntas do questionário

As opções de resposta serão apresentadas nos itens seguintes do artigo junto com a análise de resultados.

\subsection{Aplicação do questionário}

O questionário foi aplicado utilizando-se o Hotjar (www.hotjar.com), uma ferramenta específica para coleta e análise de questionários online. Optou-se por essa ferramenta em função de outras análises que também seriam feitas por ela.

O questionário era de preenchimento voluntário e anônimo, com perguntas fechadas de múltipla escolha. Ao começar a rolar a página inicial do site, uma pequena caixa surgia no canto inferior da tela mostrando o questionário. O questionário ficou disponível para recebimento de respostas entre os dias 19/01/2016 e 29/01/2016 (Figura 3).

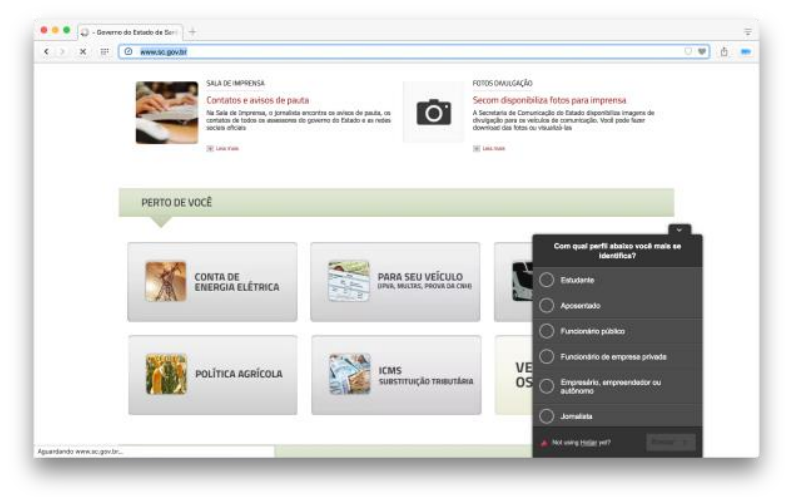

Figura 3: Captura de tela mostrando como o formulário foi apresentado aos respondentes. Fonte: autores.
Nas próximas etapas foram apresentadas as perguntas fechadas e categorizadas.

\section{$3 \quad$ Análise das respostas}

\subsection{Perfil dos respondentes}

Durante os 11 dias em que esteve no ar, foram coletadas 1.407 respostas para a primeira pergunta, 884 respostas para a segunda e 736 respostas para a terceira , dentre um universo amostral de 36.984 pessoas que visitaram o site durante este período.

O público mais alcançado pelo questionário e interessado em responder as perguntas foram, nas duas primeiras posições, pessoas que se identificaram como funcionários públicos $(32 \%)$ e estudantes (28\%). O público jornalista com $11 \%$ de respondes ficou na $4^{\mathrm{a}}$ posição (Figura 4 ). 


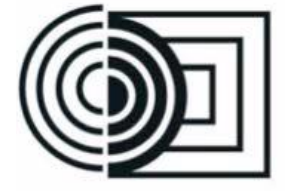
CINAHPA

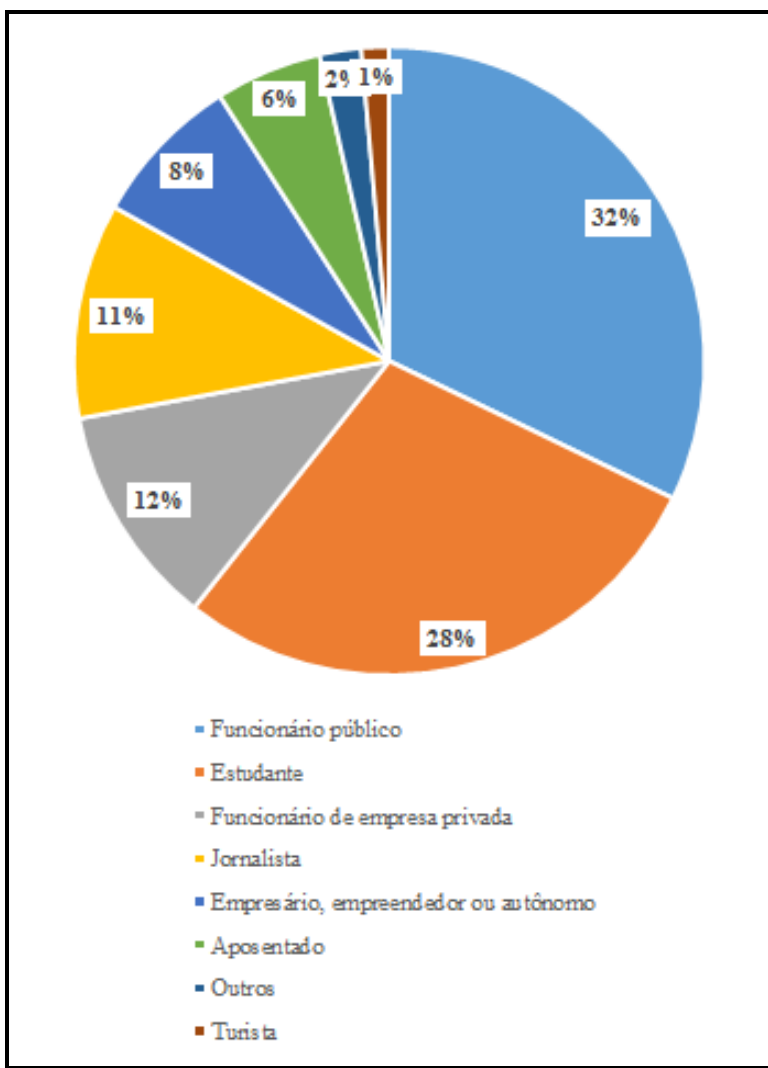

Gráfico 1: Representação da porcentagem de respondentes de cada público da pesquisa

Quanto ao expressivo número de estudantes é possível considerar que são pesquisadores em busca de informações relativas ao governo e ao estado de Santa Catarina, que procuram no principal site do Governo um direcionamento para busca de dados sobre o estado.

Para o universo amostral de respondentes da pergunta "a" foi possível atingir um nível de significância de $87,70 \%$, considerando uma margem de erro de $1 \%$ e uma probabilidade de escolha de cada alternativa igual a 0,125 . Ou seja, a resposta obtida reflete a expectativa de aproximadamente $90 \%$ dos visitantes do site.

\subsection{Interesses por público}

Após a identificação da quantidade de respondentes por tipo de público, foi possível, por meio da pergunta " $b$ " do questionário, identificar entre uma gama pré-estabelecida de opções, quais $16^{\circ}$ Ergodesign - Congresso Internacional de Ergonomia e Usabilidade de Interfaces Humano Tecnológica: Produto, Informações Ambientes Construídos e Transporte

$16^{\circ}$ USIHC - Congresso Internacional de Ergonomia e Usabilidade de Interfaces Humano Computador

CINAHPA | 2017 - Congresso Internacional de Ambientes Hipermídia para Aprendizagem.

são os conteúdos que buscavam ou esperavam encontrar no site avaliado. Também é relevante argumentar que os tipos de públicos elencados para essa pesquisa não podem ser desdobrados em personas e nem considerados como tal para uma possível segmentação das áreas do canal de internet, pois foram criadas com base em estereótipos e não em objetivos e comportamentos. (COOPER et. al., 2007).

Apesar dessa limitação, os públicos levantados apresentam informações valiosas sobre o perfil de busca por informação e oferece linhas gerais para direcionamento de melhorias pontuais na arquitetura da informação do site, ou, um ponto de partida para construção de um portal totalmente remodelado com base em pesquisa ergonômica e design de interação.

Na tabela é possível verificar de forma abrangente quais os conteúdos mais esperados ou buscados pelos pesquisados. Dentro de uma gama controlada de opções (Tabela 1).

Na Tabela 2 relaciona-se os perfis de acesso do site com os conteúdos de interesse, o que nos permite chegar a conclusões bastante interessantes. A primeira delas é que muitos estudantes buscam o site do Governo do Estado pelos mais diversos motivos. Uma pesquisa analítica pode identificar se esse público chega ao site por buscadores, procurando termos que os fazem chegar ao portal oficial do governo do estado. 


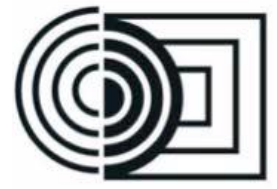
CINAHPA

\begin{tabular}{|l|r|}
\hline $\begin{array}{l}\text { Dados sobre Santa Catarina (Cultura, } \\
\text { turismo, regiões, economia...) }\end{array}$ & $2,94 \%$ \\
$\begin{array}{l}\text { Informações sobre o Governo e seus } \\
\text { órgãos e secretarias }\end{array}$ & $8,82 \%$ \\
$\begin{array}{l}\text { Legislação, decretos e atos } \\
\text { Notícias, releases, matérias, } \\
\text { pronunciamentos do governo }\end{array}$ & $8,82 \%$ \\
$\begin{array}{l}\text { Oportunidades de empregos, concursos, } \\
\text { licitações ou negócios } \\
\begin{array}{l}\text { Outros. Quais? } \\
\text { Serviços do governo estadual } \\
\text { (documentos, taxas, matriculas, etc) }\end{array}\end{array}$ & $14,71 \%$ \\
\hline
\end{tabular}

Tabela 1. Total de respostas por tipo de informação buscada.

Ao avaliar as respostas da pergunta "a" foram encontradas uma série de oportunidades a serem consideradas. A primeira delas é que grande parte do público respondente da pesquisa não condiz com o público para quem é direcionado o conteúdo atual do site: jornalistas e profissionais de veículos de imprensa. Nas áreas nobres do site (menu principal de topo da página principal), estão destacadas as principais notícias, releases de imprensa, galeria de fotos para downloads e sala de imprensa (Figura 5).

Excetuando o público estudantes poucas pessoas buscavam dados sobre Santa Catarina, cultura e turismo, o que pode significar que os respondentes do questionários são moradores de Santa Catarina, que conhecem o estado relativamente.

Outra avaliação que pode ser feita é que respondentes com uma porcentagem considerável de respostas: funcionário de empresa privada (12\%) e empresários, empreendedores ou autônomos (8\%) não possuem, mesmo que discretamente, nenhum tipo de conteúdo ou funcionalidade direcionado a esses usuários. $16^{\circ}$ Ergodesign - Congresso Internacional de Ergonomia e Usabilidade de Interfaces Humano Tecnológica: Produto, Informações Ambientes Construídos e Transporte

$16^{\circ}$ USIHC - Congresso Internacional de Ergonomia e Usabilidade de Interfaces Humano Computador

CINAHPA | 2017 - Congresso Internacional de Ambientes Hipermídia para Aprendizagem.

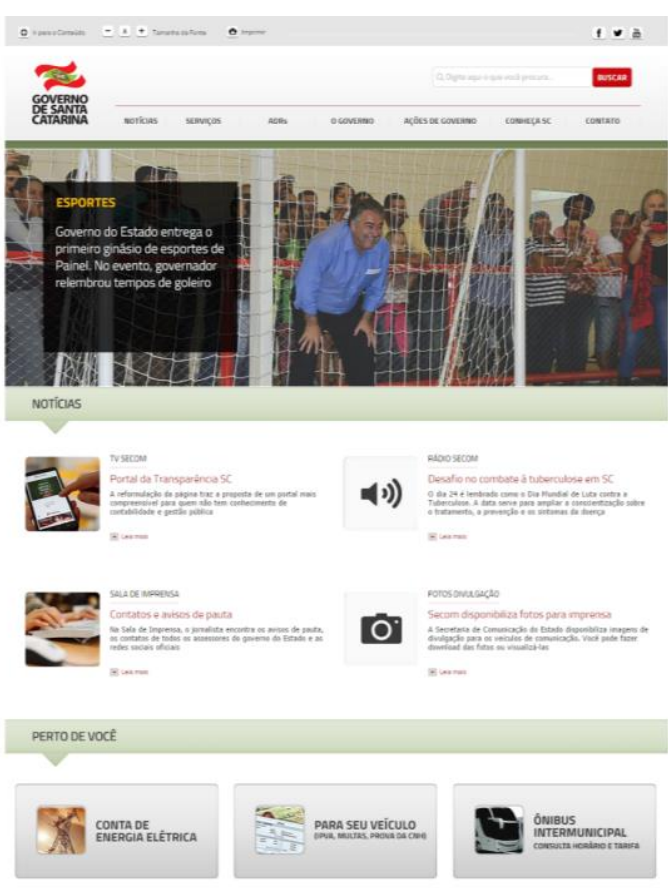

Figura 3. Representação das grandes áreas do site representadas no menu principal: Notícias, Serviços, ADRS, O Governo, Ações de Governo, Conheça SC e Contato (print em 26/03/2017)

A maior parte dos públicos que buscam por Oportunidades de empregos, concursos, licitações ou negócios são funcionários de empresas privadas. Informação que não se encontra disponível em nenhuma área do site atualmente.

Grande parte do público - os jornalistas em destaque, com $85 \%$, está em busca de Notícias, releases, matérias, pronunciamentos do governo. Ou seja, um conteúdo que já existe mas que pode estar com melhor destaque no site.

As opções de interesse Serviços do governo estadual (documentos, taxas, matrículas, etc) são pouco buscadas por todos os públicos em relação às demais, o que pode demonstrar que os catarinenses não veem o portal do governo estadual como uma ferramenta centralizadora de serviço. Ao mesmo tempo, pode simbolizar uma oportunidade de resgatar esse público para acessar os serviços e ter acesso às notícias e releases, conteúdo mais abundante e atualizado disponível hoje. 


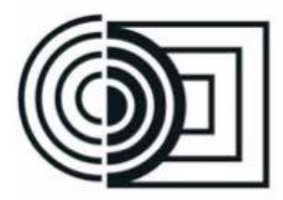

$16^{\circ}$

ERGODESIGN USIHC CINAHPA $16^{\circ}$ Ergodesign - Congresso Internacional de Ergonomia e Usabilidade de Interfaces Humano Tecnológica: Produto, Informações Ambientes Construídos e Transporte

$16^{\circ}$ USIHC - Congresso Internacional de Ergonomia e Usabilidade de Interfaces Humano Computador

CINAHPA | 2017 - Congresso Internacional de Ambientes Hipermídia para Aprendizagem.
Considerando apenas o número de respondentes para a segunda pergunta, o nível de confiança foi de 79,10\%. Para tal cálculo foi considerado uma margem de erro de $1 \%$ e uma probabilidade de escolha de cada resposta igual a 0,167 . Ou seja, a resposta obtida representa a expectativa de quase $80 \%$ dos visitantes do site.

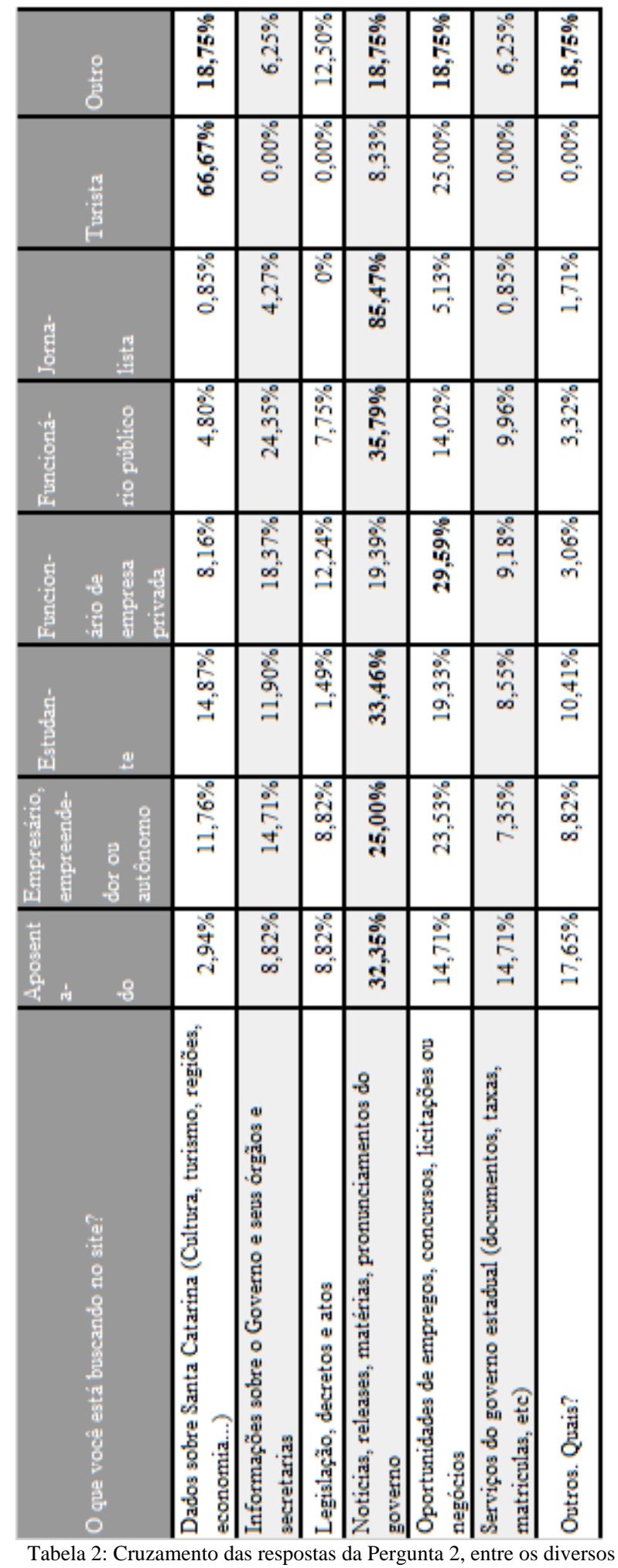
perfis de público e os diversos conteúdos disponíveis 


\section{$16^{\circ}$ \\ ERGODESIGN USIHC CINAHPA}

$16^{\circ}$ Ergodesign - Congresso Internacional de Ergonomia e Usabilidade de Interfaces Humano Tecnológica: Produto, Informações Ambientes Construídos e Transporte

$16^{\circ}$ USIHC - Congresso Internacional de Ergonomia e Usabilidade de Interfaces Humano Computador

CINAHPA | 2017 - Congresso Internacional de Ambientes Hipermídia para Aprendizagem.

\section{3 Índice de satisfação}

O Net Promoter Score é uma popular metodologia baseada numa única pergunta sobre a lealdade e satisfação do consumidor. (REICHHELD, 2003; NIELSEN, 2004; SAURO \& LEWIS, 2012) A pergunta original ("Qual a probabilidade de você recomendar este produto para um amigo ou colega?") foi adaptada para o contexto desta pesquisa. As opções de resposta variam de 0 a 10, e são agrupadas em 3 segmentos:

- Promotores: respostas de 9 a 10

- Passivos: respostas de 7 a 8

- Detratores: respostas de 0 a 6

Sauro (2012) explica que, ao subtrair o percentual de detratores pelo percentual de promotores, descobre-se a pontuação líquida de promotores (D - P = NPS), onde quanto maior o número, maior o índice de lealdade e satisfação (mais promotores que detratores).

Com base nas 736 respostas obtidas, foi possível identificar o índice NPS para cada público (Figura $6)$ :

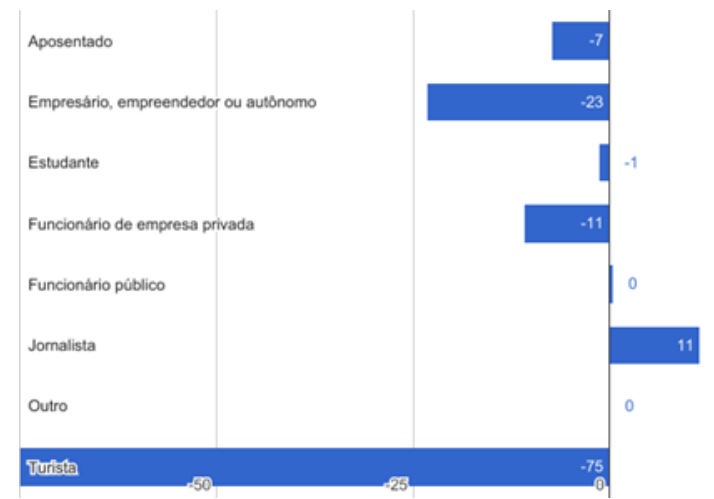

Figura 6: Representação gráfica do índice NPS de acordo com cada público respondente. Fonte: autores

Aqui percebe-se que o único público com percepção positiva do site são Jornalistas, com NPS de $11 \%$. Todos os demais públicos possuem percepções neutras ou negativas, especialmente empresários e turistas, com $-23 \%$ e $-75 \%$ respectivamente.

O índice NPS geral, considerando todas as respostas, foi de $-3 \%$, o que pode ser considerado um resultado levemente negativo.

Considerando apenas o número de respondentes para a pergunta "c", o nível de confiança foi obtido de $82,89 \%$. Para tal cálculo foi considerado uma margem de erro de $1 \%$ e uma probabilidade de escolha de cada resposta igual a 0,091 . Ou seja, a resposta obtida representa a expectativa da grande maioria dos visitantes do site.

No Portal atual é possível verificar uma atualização constante de conteúdo, em texto, fotos, audios e audiovisuais. Apesar das informações serem produzidas pela assessoria de imprensa, com foco em conteúdo primário para jornalistas e profissionais de veículos de comunicação, percebese no questionário que uma boa parcela do público "não jornalista" também busca notícias, releases e pronunciamentos. Isso gera uma possibilidade de manter a frequência de conteúdo, mas com um direcionamento mais específico de tom e linguagem para gerar engajamento e dando maior visibilidade para algumas áreas, como a TV Secom, que contempla uma produção contínua de vídeos para o cidadão e que não está apresentada na totalidade no site atual. Podendo estar, inclusive, em destaque na capa do site que é o espaço onde devem estar apresentados os conteúdos mais persuasivos do site. (RODRIGUES, 2006)

Uma das recomendações relevantes em relação ao conteúdo, é o retorno sobre a busca de "serviços do Governo Estadual" (14,71\%). O Site vigente não possui uma área de serviços, somente um link no menu principal direcionando o usuário para outro site governamental - o Perto de Você - nesse caso, recomenda-se que o site integre mais informações de serviços focados no cidadão. 


\section{$16^{\circ}$ \\ ERGODESIGN USIHC CINAHPA}

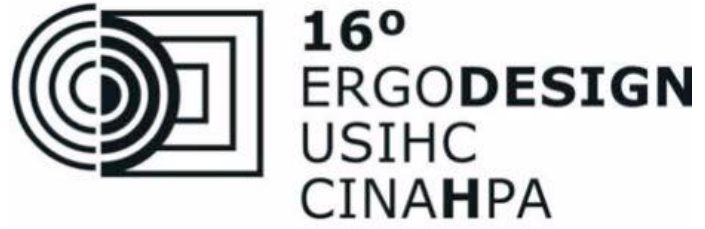

\subsection{Conclusão}

Os cientistas sociais perceberam há muito tempo que os comportamentos humanos possuem muitas variáveis para depender exclusivamente de dados quantitativos para compreendê-los. (COOPER et. al., 2007). Por isso, os pesquisadores autores deste artigo, recomendam que para uma avaliação mais completa e sofisticada, profissionais de design e usabilidade, utilizem esse artigo como ponto de partida para futuras análises utilizando outras técnicas de ergonomia que avaliem aspectos também relevantes para a reconstrução ou melhoria do portal do Governo do Estado de Santa Catarina.

Ao observar os dados coletados, e iniciar as proposições de melhorias, esse artigo sugere-se utilizar o o estudo "Conteúdo, Usabilidade e Funcionalidade: três dimensões para a avaliação de portais estaduais de Governo Eletrônico na Web" (2003) de Patrícia Montinho Vilella, como balizador. nele estão descritas recomendações focadas nesses três aspectos gerais.

Existem outras recomendações para testes é a elaboração de desempenho do site relacionado as técnicas de SEO, porém seria necessária aplicação de outras análises, além do questionário com o usuário para gerar um diagnóstico mais elaborado.

Um item que não é explicitado pela pesquisa, mas certamente faria diferença em relação a navegação e utilização do site é pensar na produção de uma versão mobile. Mesmo tendo sido reformulado em 2013 o www.sc.gov.br não possui uma versão responsiva.

Testes de usabilidade no portal atual e técnicas de Ergonomia Cognitiva como focus group e avaliação de dados de analytics para sugerir novos "gaps" na arquitetura da informação também estão na gama de avaliações que podem fazer com que o site do governo estadual possa finalmente chegar a um objetivo pragmático: ajudar a criar um ambiente adequado às necessidades do usuário. $16^{\circ}$ Ergodesign - Congresso Internacional de Ergonomia e Usabilidade de Interfaces Humano Tecnológica: Produto, Informações Ambientes Construídos e Transporte

$16^{\circ}$ USIHC - Congresso Internacional de Ergonomia e Usabilidade de Interfaces Humano Computador

CINAHPA | 2017 - Congresso Internacional de Ambientes Hipermídia para Aprendizagem.

\section{Referências Bibliográficas}

AGUNE, Roberto et al. Dá pra Fazer.: Gestão do Conhecimento e Inovação no Setor Público. São

Paulo: Secretaria de Planejamento e

Desenvolvimento Regional, 014. 167 p.

BARBETTA, Pedro Alberto. Estatística: Aplicada as ciências sociais. 9. ed. Florianópolis: Ufsc, 2015.315 p.

COOPER, Alan; REIMANN, Robert; CRONIN, Dave. About Face: The Essentials of Interaction Design. 3a ed. Indianápolis: Wiley Publishing, Inc., 2007. 609 p.

COOPER, Alan et al. About Face: the essentials of interaction design. 4a ed. John Wiley \& Sons, 2014.

LEMOS, André; MAMEDE, José; NÓBREGA, Rodrigo; PEREIRA, Silvano; MEIRELLES, Luize. Cidade, tecnologia e interfaces . Análise de interfaces de portais governamentais brasileiros . Uma proposta metodológica. Revista Fronteiras, Unisinos, v. 2, p. 117-136, 2004

NIELSEN, Jakob; Keep online surveys short. 2004. Disponível em: <https://www.nngroup.com/ articles/keep-online-surveys-short/>. Acesso em 27 mar. 2017.

PREECE, Jenny; SHARP, Helen; ROGERS, Yvonne. Design de Interação: Além da Interação Homem-Computador. Bookman, Porto Alegre, RS. 2002.

REICHHELD, Frederick F. The one number you need to grow. Harvard Business Review, v. 81, n. 12, p. 46-55, 2003.

RODRIGUES, Bruno. WebWriting: Redação e informação para web. Rio de Janeiro: Brasport, 2006. $112 \mathrm{p}$.

ROVER, Aires José; GALINDO, Fernando. O governo eletrônico e suas múltiplas facetas. Zaragoza: Prensas Universitárias de Zaragoza, 2010. $341 \mathrm{p}$. 


\section{$16^{\circ}$ \\ ERGODESIGN USIHC CINAHPA}

$16^{\circ}$ Ergodesign - Congresso Internacional de Ergonomia e Usabilidade de Interfaces Humano Tecnológica: Produto, Informações Ambientes Construídos e Transporte

$16^{\circ}$ USIHC - Congresso Internacional de Ergonomia e Usabilidade de Interfaces Humano Computador

CINAHPA | 2017 - Congresso Internacional de Ambientes Hipermídia para Aprendizagem.

SAURO, Jeff. \& LEWIS, James .R. Quantifying the user experience: Practical statistics for user research. Elsevier; 2012.

TRIOLA, Mario F. Introdução à estatística. 10 ed. Rio de Janeiro: LTC, 2008.

VILELLA, Renata Moutinho. Conteúdo, usabilidade e funcionalidade: três dimensões para a avaliação de portais estaduais de governo eletrônico na web. 2003. $263 \mathrm{f}$.

Dissertação (Mestrado) - Curso de Ciência da Informação, Departamento de Escola de Ciência da Informação, Universidade Federal de Minas Gerais, Belo Horizonte, 2003. 